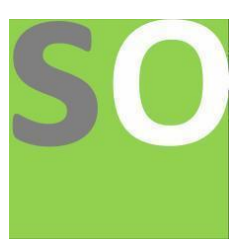

Article title: Review of Toxins Associated with Autoimmune Diseases

Authors: Domina Petric[1]

Affiliations: Clinical pharmacology and toxicology, University Hospital Center, Soltanska 1, 21000 Split, Croatia[1]

Orcid ids: 0000-0001-5609-1675[1]

Contact e-mail: domina.petric@gmail.com

License information: This work has been published open access under Creative Commons Attribution License $\mathrm{http}: / / c r e a t i v e c o m m o n s . o r g / l i c e n s e s / b y / 4.0 /$, which permits unrestricted use, distribution, and reproduction in any medium, provided the original work is properly cited. Conditions, terms of use and publishing policy can be found at https://www.scienceopen.com/.

Preprint statement: This article is a preprint and has not been peer-reviewed, under consideration and submitted to ScienceOpen Preprints for open peer review.

DOI: 10.14293/S2199-1006.1.SOR-.PPMAW3U.v1

Preprint first posted online: 21 October 2021

Keywords: autoimmunity, toxicology, toxins, immunology 


\title{
Review of Toxins Associated with Autoimmune Diseases
}

\author{
Domina Petric, MD
}

\begin{abstract}
Aim of this article is to review the literature about the toxins that might be involved in the pathogenesis of autoimmune diseases. Almost $70 \%$ of all autoimmune diseases are caused by environmental factors, including toxic chemicals. Genetic factors contribute to approximately $30 \%$ of all autoimmune diseases.
\end{abstract}

\section{INTRODUCTION}

Studies have shown that genetic predisposition accounts for approximately $30 \%$ of all autoimmune diseases. The rest, $70 \%$, are due to environmental factors, including toxic chemicals, dietary components, gut dysbiosis, and infections ${ }^{1}$.

\section{TRICHLOROETHYLENE}

Trichloroethylene (TCE) is an industrial solvent known for being neurotoxic, hepatotoxic, nephrotoxic, immunotoxic and carcinogenic. Cooper and coworkers reviewed the literature about the role of TCE in autoimmunity, and concluded that the consistency among the studies and the concordance between the studies in mice and humans support an etiologic role of TCE in autoimmune disease, but multi-site collaborations and studies of preclinical immune markers are needed to further develop this field of research ${ }^{2}$.
Substantial evidence from mechanistic, clinical, and epidemiologic studies indicates that exposure to TCE and/or its metabolites (including chloral hydrate, trichloracetic acid, trichloracetaldehyde hydrate, and dichloracetyl chloride) could influence the incidence of autoimmune disorders. Research on autoimmune mouse models, including the $\mathrm{MRL}^{+/+}$lupus mouse, has provided strong and consistent support for a role of TCE. This has included studies of exposures at environmentally relevant concentrations through multiple routes (inhalational, dermal, and oral). Studies of humans with high occupational or environmental exposures have also shown links between TCE and inflammatory immune responses, systemic sclerosis, and severe generalized hypersensitivity skin disorder ${ }^{3}$. 


\section{DRUG-INDUCED AUTOIMMUNITY}

The chemicals most often associated with development of autoimmunity in humans are medications. A large list of drugs have been shown to induce systemic lupus erythematosus (SLE)-like disease, but procainamide and hydralazine are considered to be of high risk ${ }^{4}$.

\section{SILICA}

The association of silica and development of systemic autoimmune diseases such as SLE and scleroderma, stems from exposure during occupations such as mining, construction, glass and pottery production $^{5}$.

\section{ASBESTOS}

Asbestos is another naturally occurring silicate mineral, composed of long, thin fibrous crystals. Several epidemiological studies have linked exposure to asbestos to autoimmune diseases ${ }^{6}$.

A case-control study among the current and former residents of Libby who had worked at the vermiculite mine revealed increased self-reporting of autoimmune diseases including systemic lupus erythematosus, scleroderma, and rheumatoid arthritis ${ }^{7}$.

\section{TOXIC OIL SYNDROME}

Xenobiotic-induced scleroderma, or pseudoscleroderma, has been associated with occupational exposures, especially occupational exposure to solvents ${ }^{8}$.

In the early 1980s in Spain, ingestion of adulterated cooking oil lead to an outbreak of pseudoscleroderma. The causative agent was identified as rapeseed oil, originally destined for industrial use but refined to remove the anilide denaturant and then sold as cooking oil for human consumption. Thousands of people were ultimately affected with more than 1,000 deaths being ascribed to what is called Toxic Oil Syndrome?

\section{METAL-INDUCED AUTOIMMUNITY}

Mercury, silver and gold all produce autoimmunity in mice but the pathological consequences differ, with silver and gold exposure resulting in a less severe response that typically includes the production of anti-nuclear antibodies but lacks glomerular deposits of immunoglobulin and complement ${ }^{10-13}$.

Human exposure to mercury has been implicated as an environmental trigger in the induction of autoimmunity, although a non-autoimmune-mediated nephropathy is the more common outcome $\mathrm{e}^{14,15}$. 


\section{IODINE}

Autoimmune thyroiditis, also known as chronic lymphocytic or Hashimoto's thyroiditis, is characterized by autoantibodies to thyroid-specific antigens such as thyroglobulin and thyroperoxidase that lead to inflammation and eventual impairment of the thyroid gland ${ }^{16}$.

Excess iodine ingestion has been identified as a contributing factor in the induction and exacerbation of autoimmune thyroiditis ${ }^{17,18}$.

TIENILIC ACID, DIHYDRALAZINE, HALOTHANE

Various chemicals and drugs have been implicated in autoimmune liver diseases including tienilic acid, dihydralazine, and halothane in autoimmune hepatitis ${ }^{19}$.

Primary biliary cirrhosis which is characterized by anti-mitochondrial antibodies is also argued to be associated with environmental factors ${ }^{20}$.

\section{PRISTANE}

Tetramethylpentadecane (TMPD) is a common constituent of mineral oil and is found in a number of processed foods made for human consumption. It is also known as pristane. Exposure can elicit lipogranulomas (follicular lipidosis), a chronic inflammatory response, in a number of organs (liver, spleen, lymph $\left.\operatorname{nodes}^{21}\right)$.

\section{TCDD}

The halogenated aromatic hydrocarbon 2,3,7,8-tetrachlorodibenzo-p-dioxin (TCDD) is the most potent of the dioxins and is an unintentional by-product of many industrial processes. TCDD is also a contaminant of the herbicide Agent Orange $^{22}$. Previous epidemiological studies suggest that while TCDD does influence the human immune system there is little evidence of autoimmunity ${ }^{4}$.

\section{HEXACHLOROBENZENE}

Exposure to the fungicide hexachlorobenzene (HCB) is associated with a form of hepatic porphyria called porphyria turcica, which resembles porphyria cutanea tarda, a disease caused by altered porphyrin metabolism. Porphyria turcica is associated with bullous skin lesions, mainly in sun-exposed skin areas, that heal with severe scars, primarily affects children 6-16 years of age ${ }^{23}$.

Exposure to $\mathrm{HCB}$ can also produce neurological, dermatological, and orthopaedic abnormalities that may persist for decades ${ }^{24}$. 


\section{SMOKING}

Numerous case-control and cohort studies have demonstrated higher risk for the development of rheumatoid arthritis (RA) in relation to smoking history, with a higher risk in rheumatoid factor (RF)positive or ACPA-positive $\mathrm{RA}^{25}$.

There appears to be a higher risk associated with greater exposure, in particular, after 10 pack-years of smoking in women, and the risk of RA remains elevated for up to 20 years after smoking cessation $^{26}$. A meta-analysis of the studies of smoking and thyroid disease suggests that current smoking results in higher risk for both Graves' disease and Hashimoto thyroiditis. Cigarette smoking has been reported as a risk factor for Graves' ophthalmopathy in particular ${ }^{27}$.

The relationship between smoking and inflammatory bowel disease is complex in that it is likely that current smoking contributes to the development of Crohn's disease, but is protective for the development of ulcerative colitis ${ }^{28,29}$.

\section{HAIR DYES, COSMETIC PRODUCTS}

Permanent hair dyes containing aromatic amines could be a risk factor for SLE, but the most carefully conducted epidemiologic studies have failed to identify an association between hair dyes and $\mathrm{SLE}^{30,31}$. Investigation conducted by Cooper and coworkers (2010) found an association between employment involving nail polish or nail applications and risk of $\mathrm{SLE}^{30}$. The use of hair dyes was significantly associated with a higher risk of primary biliary cirrhosis (PBC) in a study conducted in the United Kingdom ${ }^{32}$.

In a U.S. study, nail polish use was significantly more frequent among women with PBC than among control women ${ }^{33}$.

The single case-control study of RA found that women who were occupationally exposed to hairdressing chemicals were at greater risk than unexposed women for developing $\mathrm{RA}^{34}$.

\section{IONIZING RADIATION}

There is convincing evidence that external radiation treatment for cancer increases the risk of autoimmune thyroiditis and Graves' disease, especially in treatment for cancers of the neck region ${ }^{35,36}$.

A pooled analysis of two case-control studies of multiple sclerosis (MS) conducted in Sweden reported that occupational exposure to ionizing radiation (in hospitals or industry) was associated with over four-fold higher risk of $\mathrm{MS}^{37}$. 


\section{BIOLOGICAL FACTORS AND INFECTIONS}

Ingestion of gluten contributes to the development of gluten-sensitive enteropathy (GSE). Ingestion of certain lots of L-tryptophan contributes to the development of eosinophilia-myalgia syndrome. Epstein-Barr virus infection contributes to the development of MS. Early introduction of complex foods contributes to development of diabetes type 1 and GSE. Low vitamin D dietary intake and blood level contribute to development of $\mathrm{MS}^{25}$.

\section{CONCLUSION}

Studies have shown that almost $70 \%$ of all autoimmune diseases are caused by environmental factors, including toxic chemicals, whilst genetic factors contribute to approximately $30 \%$ of all autoimmune diseases. Therefore, further investigation on toxic chemicals that might be associated with pathogenesis of autoimmune diseases is mandatory. Prevention of autoimmunity in humans relies greatly on the prevention of exposure to incriminated toxins that can cause, trigger and/or worsen autoimmune diseases. Immune-toxins must be replaced with at least less toxic, if not non-toxic chemicals. In addition to that, healthy balanced diet and healthy gut microbiome also play a very important role.

\section{REFERENCES}

1. Vojdani A, Pollard KM, Campbell AW. Environmental triggers and autoimmunity. Autoimmune Dis. 2014;2014:798029.

2. Cooper GS, Makris SL, Nietert PJ, Jinot J. Evidence of autoimmune-related effects of trichloroethylene exposure from studies in mice and humans. Environ Health Perspect. 2009;117(5):696-702.

3. Weinhold B. A clearer view of TCE: evidence supports autoimmune link. Environ Health Perspect. 2009;117(5):A210.

4. Pollard KM, Hultman P, Kono DH. Toxicology of autoimmune diseases. Chem Res Toxicol. 2010;23(3):455-466.

5. Parks CG, Conrad K, Cooper GS. Occupational exposure to crystalline silica and autoimmune disease. Environ Health Perspect. 1999;107(5):793802.

6. Otsuki T, Maeda M, Murakami S, et al. Immunological effects of silica and asbestos. Cell Mol Immunol. 2007;4(4):261-8.

7. Noonan CW, Pfau JC, Larson TC, Spence MR. Nested case-control study of autoimmune disease in an asbestos-exposed population. Environ Health Perspect. 2006;114(8):1243-7.

8. Kettaneh A, Al Moufti O, Tiev KP, et al. Occupational exposure to solvents and genderrelated risk of systemic sclerosis: a metaanalysis of case-control studies. J Rheumatol. 2007;34(1):97103.

9. Posada de la Paz M, Philen RM, Borda AI. Toxic oil syndrome: the perspective after 20 years. Epidemiol Rev. 2001;23(2):231-47. 
10. Hultman P, Bell LJ, Enestrom S, Pollard KM. Murine susceptibility to mercury. I. Autoantibody profiles and systemic immune deposits in inbred, congenic, and intra-H-2 recombinant strains. Clin Immunol Immunopathol. 1992;65:98-109.

11. Hultman $\mathrm{P}$, Johansson $\mathrm{U}$, Turley $\mathrm{SJ}$, et al. Adverse immunological effects and autoimmunity induced by dental amalgam and alloy in mice. Faseb J. 1994;8:1183-90.

12. Havarinasab S, Johansson U, Pollard KM, Hultman P. Gold causes genetically determined autoimmune and immunostimulatory responses in mice. Clin Exp Immunol. 2007;150:179-88.

13. Johansson U, Hansson-Georgiadis H, Hultman P. Murine silver-induced autoimmunity: silver shares induction of antinucleolar antibodies with mercury, but causes less activation of the immune system. Int Arch Allergy Immunol. 1997;113:43243.

14. Silva IA, Nyland JF, Gorman A, et al. Mercury exposure, malaria, and serum antinuclear/antinucleolar antibodies in Amazon populations in Brazil: a cross-sectional study. Environ Health. 2004;3(1):11.

15. Abréu Vélez AM, Warfvinge G, Herrera WL, et al. Detection of mercury and other undetermined materials in skin biopsies of endemic pemphigus foliaceus. Am J Dermatopathol. 2003;25(5):384-91.

16. Burek CL, Rose NR. Autoimmune thyroiditis and ROS. Autoimmun Rev. 2008;7:530-7.

17. Bournaud C, Orgiazzi JJ. Iodine excess and thyroid autoimmunity. $J$ Endocrinol Invest. $2003 ; 26(2): 49-56$.
18. Tomer Y, Huber A. The etiology of autoimmune thyroid disease: a story of genes and environment. J Autoimmun. 2009;32(3-4):231-9.

19. Obermayer-Straub P, Strassburg CP, Manns MP. Autoimmune hepatitis. $J$ Hepatol. 2000;32(1):181-97.

20. Rieger R, Gershwin ME. The $X$ and why of xenobiotics in primary biliary cirrhosis. $J$ Autoimmun. 2007;28(2-3):76-84.

21. Cruickshank B, Thomas MJ. Mineral oil (follicular) lipidosis: II. Histologic studies of spleen, liver, lymph nodes, and bone marrow. Hum Pathol. 1984;15(8):731-7.

22. Young AL, Giesy JP, Jones PD, Newton M. Environmental fate and bioavailability of Agent Orange and its associated dioxin during the Vietnam War. Environ Sci Pollut Res Int. 2004;11(6):359-70.

23. Michielsen CC, van Loveren H, Vos JG. The role of the immune system in hexachlorobenzeneinduced toxicity. Environ Health Perspect. 1999;107(5):783-92.

24. Cripps DJ, Peters HA, Gocmen A, Dogramici I. Porphyria turcica due to hexachlorobenzene: a 20 to 30 year follow-up study on 204 patients. $\mathrm{Br} J$ Dermatol. 1984;111(4):413-22.

25. Miller FW, Alfredsson L, Costenbader KH, et al. Epidemiology of environmental exposures and human autoimmune diseases: findings from a National Institute of Environmental Health Sciences Expert Panel Workshop. J Autoimmun. 2012;39(4):259-271. 
26. Costenbader KH, Feskanich D, Mandl LA, Karlson EW. Smoking intensity, duration, and cessation, and the risk of rheumatoid arthritis in women. Am J Med. 2006;119(6):503.e1-9.

27. Vestergaard P. Smoking and thyroid disorders-a meta-analysis. Eur $J$ Endocrinol. 2002;146(2):153-61.

28. Calkins BM. A meta-analysis of the role of smoking in inflammatory bowel disease. Dig Dis Sci. 1989;34(12):1841-54.

29. Mahid SS, Minor KS, Soto RE, Hornung CA, Galandiuk S. Smoking and inflammatory bowel disease: a meta-analysis. Mayo Clin Proc. 2006;81(11):1462-71.

30. Cooper GS, Wither J, Bernatsky S, et al. Occupational and environmental exposures and risk of systemic lupus erythematosus: silica, sunlight, solvents. Rheumatology (Oxford). 2010;49(11):2172-80.

31. Sánchez-Guerrero J, Karlson EW, Colditz GA, et al. Hair dye use and the risk of developing systemic lupus erythematosus. Arthritis Rheum. 1996;39(4):657-62.

32. Prince MI, Ducker SJ, James OF. Case-control studies of risk factors for primary biliary cirrhosis in two United Kingdom populations. Gut. 2010;59(4):508-12.

33. Gershwin ME, Selmi C, Worman HJ, et al, USA PBC Epidemiology Group. Risk factors and comorbidities in primary biliary cirrhosis: a controlled interview-based study of 1032 patients. Hepatology. 2005;42(5):1194-202.

34. Olsson AR, Skogh T, Wingren G. Occupational determinants for rheumatoid arthritis. Scand $J$ Work Environ Health. 2000;26(3):243-9.
35. Hancock SL, Cox RS, McDougall IR. Thyroid diseases after treatment of Hodgkin's disease. $N$ Engl J Med. 1991;325(9):599-605.

36. Jereczek-Fossa BA, Alterio D, Jassem J, et al. Radiotherapy-induced thyroid disorders. Cancer Treat Rev. 2004;30(4):369-84.

37. Axelson O, Landtblom AM, Flodin U. Multiple sclerosis and ionizing radiation. Neuroepidemiology. 2001;20(3):175-8. 